\title{
LUPA NH 2.0: evolução tecnológica para fortalecimento da comunicação social hiperlocal
}

LUPA NH2.0: technological evolution for strengthening of the hyperlocal social communication

LUPA NH 2.0: evolución tecnológica para el fortalecimiento de los medios hiperlocales

\begin{abstract}
Walter Teixeira Lima Junior
Docente do Mestrado Profissional Interdisciplinar em Inovação Tecnológica (PIT) da Universidade Federal de São Paulo (Unifesp) e do Programa de Pósgraduação em Comunicação, Cultura e Amazônia da Universidade Federal do Pará (UFPA). E-mail: walter.lima@unifesp.br
\end{abstract}

0000-0002-9423-3854

Cláudia Maria Arantes de Assis Saar Doutora em Comunicação Social da Universidade Metodista de São Paulo (UMESP). Professora do curso de jornalismo na Universidade Federal do Amapá. Líder do grupo de pesquisa COMERTEC (Comunicação, Mercado e Tecnologia). E-mail: claudiamaria@unifap.br.

0000-0002-5019-8110

\section{Wellington Pacheco Ferreira}

Mestrando do Programa de Mestrado Profissional Interdisciplinar em Inovação Tecnológica da Universidade Federal de São Paulo (Unifesp). E-mail: wpferreira@unifesp.br

\section{0-0002-5628-4917}

Recebido em: 16.02.2021.

Aceito em: 16.04.2021.

Publicado em: 01.07.2021.

\begin{abstract}
RESUMO:
O artigo analisa a evolução do projeto experimental Lupa $\mathrm{NH}$, com o envolvimento de professores e alunos da Escola Estadual Raimunda dos Passos Santos (Amapa/AP). O projeto visa criar ambiente comunicacional (conversação) e deliberação para a formação de Inteligência Social Hiperlocal, objetivando a colaboração na inserção de dados hiperlocais e produção de conteúdo jornalístico com o viés cívico/cidadão, abastecendo bases de dados locais, através de aplicativo customizado para dispositivos móveis, com informações sobre infraestrutura nas seguintes áreas: água potável; coleta e tratamento de esgoto; iluminação pública; calçadas; asfalto; limpeza urbana. O trabalho descreve o desenvolvimento aprimorado da versão 2.0
\end{abstract}

PALAVRAS-CHAVES: Hiperlocal; Jornalismo; Aplicativo; Cidadão: Lupa $\mathrm{NH}$

\section{Introdução}

O projeto experimental Lupa $\mathrm{NH}$ foi criado com o objetivo de incentivar à construção da cidadania e das mediações políticas (CASADEl, 2016, p.16), por intermédio da função social da comunicação, contando com a colaboração dos moradores, dos estudantes e dos professores da comunidade de Novo Horizonte, na cidade de Macapá (Amapá). O bairro foi escolhido pelos integrantes do projeto por ser a segunda maior comunidade em população de Macapá, de acordo com estimativas atuais, o número está em torno de 45 mil habitantes, e com inúmeras dificuldades na sua infraestrutura e de serviços públicos.

Situado na Zona Norte da capital amapaense, a região era periférica e foi gradualmente sendo ocupada a partir de 1994 (MORAIS et al., 2018, p.94), para que muitos migrantes tivessem acesso à terra e à moradia, a qual "só se viabilizou por meio de processos de ocupação de terras ociosas e da autoconstrução da moradia, gerando 


\section{Obsevisto}

assentamentos insalubres, frequentemente ocupando áreas de risco"(CARDOSO, 2016, p.29). A expansão desordenada na Zona Norte causou consequências negativas nos âmbitos social e ambiental para a cidade e, consequentemente, também para o bairro de Novo Horizonte. Os pesquisadores Palheta et. al. (2016) e Carvalho (2013) mencionam algumas dessas consequências como a segregação socioespacial, falta de investimento público, desvalorização da terra, degradação de áreas verdes e diminuição da qualidade urbana ambiental das cidades.

Figura 1: Planta Cartográfica do Bairro Novo Horizonte ${ }^{1}$

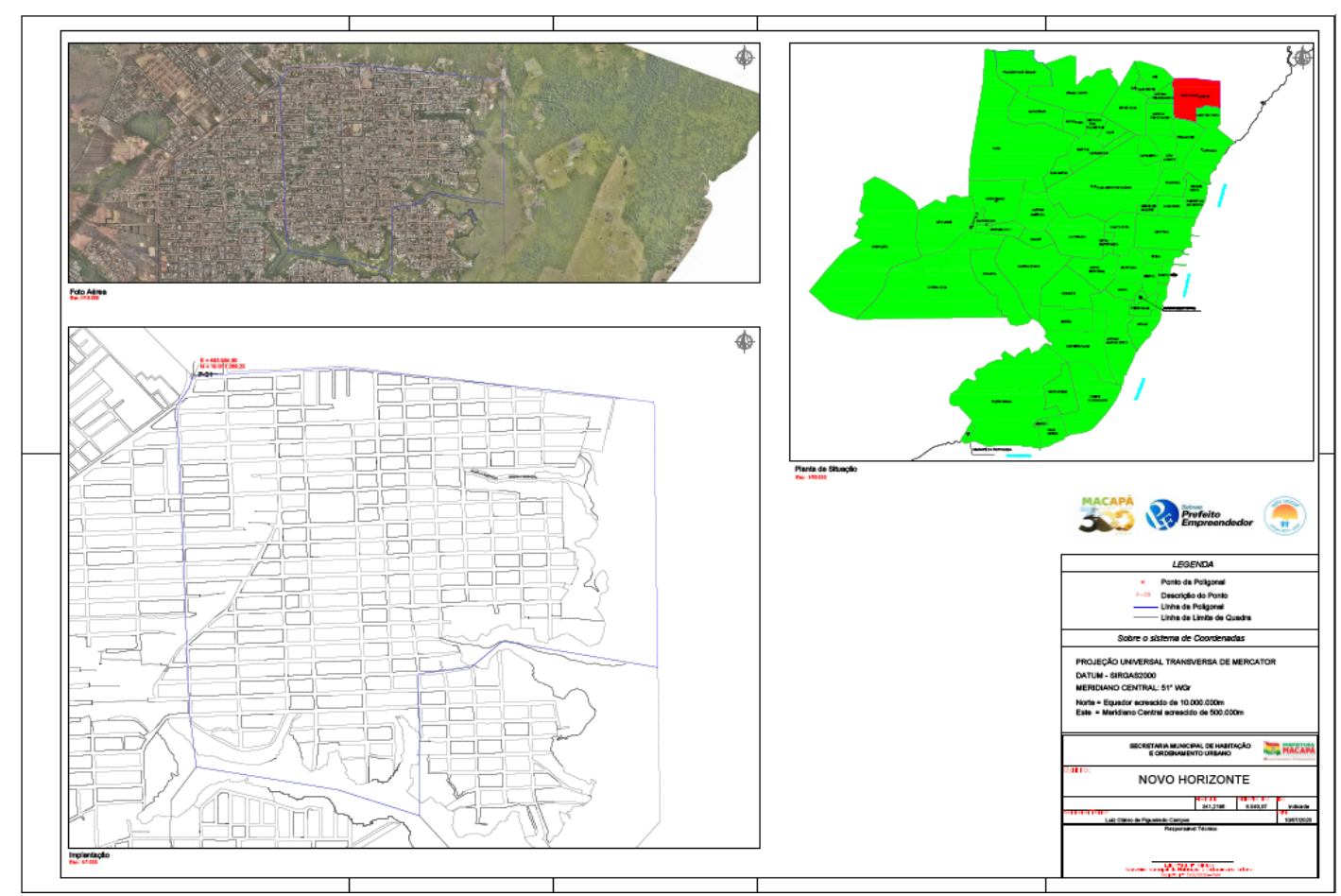

Fonte: Prefeitura de Macapá

O descaso público com a região, ao longo de décadas, proporcionou crescimento desordenado do bairro e a inexistência de políticas públicas agravou o quadro social. Para conhecer melhor as necessidades de Novo Horizonte, foram realizadas pesquisas junto à Prefeitura de Macapá, como o objetivo de coletar dados estruturados da região. Entretanto, foi revelada a inexistência de dados sobre o bairro, que atesta a impossibilidade de implantação de estratégias de política pública de forma eficiente, eficaz e efetiva. O fator importante para a escolha do bairro para implantação do projeto, foi a historicidade do local com produtos de comunicação comunitária, como a

${ }^{1}$ Disponível em < https://macapa.ap.gov.br/consulta-publica-no-001-2020-pmm-delimitacao-edefinicao-dos-bairros-de-macapa/\#plantascartograficas> Acessado em 23 de março de 2021 
Rádio Comunitária Novo Tempo e jornal impresso produzido pela comunidade ${ }^{2}$. Nesse contexto socioeconômico, o início da modelagem do projeto aconteceu, em 2017, via atividades como reuniões, visitas ao bairro, à rádio comunitária e à escola Estadual Raimunda dos Passos Santos, que foi adotada para ser base do piloto do projeto, envolvendo alunos e professores da escola (voluntários), a qual possui 2.500 alunos. A partir da escolha do bairro e das inserções na região, foi modelado projeto teórico, com viés interdisciplinar, para criação de aplicativo em telefones celulares, com o objetivo de fornecer por intermédio de sistema de geolocalização digital conectado e utilizando e de preceitos da comunicação comunitária (PERUZZO, 2007), é possível fazer com que os indivíduos se transformem em produtores de conteúdo informativo de relevância social de forma cidadã (BOWMAN; WILLIS, 2003), se valendo de ferramentas tecnológicas digitais conectadas. Nesse sentido, os voluntários, após treinamento especifico de manuseio do aplicativo e produção de conteúdo, poderão adquirir autonomia e autoridade para relatar as suas próprias histórias, por vezes ignoradas pela mídia tradicional. Como resultado, espera-se que os voluntários, conhecedores dos problemas de infraestrutura do bairro, possam abastecer bases de dados digitais locais a partir de aplicativo para dispositivos móveis customizado e/ou na Web, possibilitando a formação de datasets $^{3}$ com informação estruturada sobre a região.

Portanto, o objetivo central do projeto é a criação é a criação de uma esfera pública interconectada (BENKLER, 2006), composta pela "coesão coletiva" e pelo processo comunitário de deliberação, permitindo a formação de um ambiente participativo por meio das tecnologias de comunicação digitais conectadas, que possibilita, se for bem configurada e os voluntários estiverem bem preparados, fornecer "poder" à comunidade, influenciando a tomada de decisões locais de forma colaborativa. Esse escopo pode favorecer o envolvimento cívico, a coprodução e o compartilhamento de informação com o fim de resolver os graves problemas sociais da região. Importante ressaltar a característica fundamental do projeto. Ela difere da

\footnotetext{
${ }^{2}$ Foi realizada em visita a Rádio Comunitária Rádio Novo Tempo, que funcionava de forma precária, mas, na atualidade, está fora do ar. Sobre o Jornal, há apenas relatos de antigos moradores.

${ }^{3}$ Um conjunto de dados (Dataset) é uma coleção de itens distintos e relacionados de dados relacionados que podem ser acessados individualmente ou em combinação ou gerenciados como uma entidade inteira. Um conjunto de dados é organizado em algum tipo de estrutura de dados. Em um banco de dados, por exemplo, um conjunto de dados pode conter uma coleção de dados de negócios (nomes, salários, informações de contato, números de vendas e assim por diante). O próprio banco de dados pode ser considerado um conjunto de dados, assim como os corpos de dados dentro dele relacionados a um determinado tipo de informação, como dados de vendas para um determinado departamento corporativo. Disponível em < https://whatis.techtarget.com/definition/data-set> 24 de março de 2021
} 
finalidade da pesquisa aplicada, que é definida "por seu interesse prático, isto é, que os resultados sejam aplicados ou utilizados, imediatamente, na solução de problemas que ocorrem na realidade" (MARCONI; LAKATOS, 2002, p. 20), muitas delas ligadas a questões de comercialização produtos e soluções. Assim, o projeto se estrutura na linha experimental, como diz o termo, visa a experimentação, sendo "o experimento uma situação, criada em laboratório, com a finalidade de observar, sob controle, a relação que existe entre fenômenos " (RUDIO, 1986, p. 60).

Com essa configuração experimental, o projeto que possui como principal característica ser elaborado de forma colaborativa, sem financiamento, contando com voluntários em todas as suas etapas, se inicia com a organização de um Hackthon ${ }^{4}$. 0 evento proporcionou adensamento da modelagem tecnológica e o início da primeira versão do aplicativo, sendo desenvolvido em três partes: aplicativo para dispositivos mobile e Application Programing Interface (API) com interligações para o mapa em nuvem.

\section{Media Ecology: compondo com um ecossistema midiático}

A cidade de Macapá possui sistema midiático tradicional, com emissoras de TV (sinal aberto e a cabo), rádios e jornais impressos. Portanto, seguindo o modelo consolidado em todo território nacional, com retransmissões de conteúdos e produção de conteúdo local, muitas vezes atrelados aos interesses econômicos e políticos vigentes no Estado do Amapá, que se configuram forças poderosas em quase todos os setores da sociedade amapaense.

Compondo com o sistema midiático tradicional, redes sociais, blogs e outros dispositivos informativos baseados na Internet, formam um sistema midiático híbrido e de difícil mensuração de impacto. As plataformas de mídia social, como grupos locais no Facebook, também desempenham um papel cada vez mais importante na ecologia da mídia local (NYGREN; LECKNER; TENOR, 2018, p.1). No entanto, embora as novas plataformas sejam importantes, elas não substituem a mídia tradicional, como jornais e TV aberta e rádio, em vez disso, eles se tornam um complemento e têm funções importantes junto com as plataformas de mídia tradicionais. Assim, o sistema muda para se tornar mais 'híbrido', tanto a velha como a nova mídia mudam, no sentido de compor e formar uma nova ecologia de mídia (COLEMAN et al., 2016) Chadwick (2013) evidencia a existência de um sistema de mídia híbrido, o qual está sendo configurado

\footnotetext{
${ }^{4}$ Hackathon é um evento que reúne programadores, designers e outros profissionais ligados ao desenvolvimento de software em maratonas de trabalho com o objetivo de criar soluções específicas para um ou vários desafios.
} 
onde diferentes formas de mídia local competem com a mídia tradicional, mas coexistindo de forma interdependente entre as novas formas midiáticas e os padrões consagrado de divulgação de informação de relevância social. Esse contexto comunicacional tem sido conceituado como New Media Ecology (Ecologia da nova Mídia). No conceito, tanto a mídia nova quanto a velha encontram novos lugares no sistema (ANDERSON, 2016). Esse hibridismo é muito importante na correlação de forças midiáticas, pois há um declino da mídia local, que principalmente atua em pequenas e médias cidades. Essa diminuição pode ser notada pela redução de vendagem de veículos jornalísticos impressos e mesmo o desparecimento dos mesmos, como aconteceu em Santa Catarina, quando deixaram de circular o Diário Catarinense, o jornal de maior tiragem e mais ampla circulação em Santa Catarina, publicado desde 1986; o A Notícia, baseado em Joinville, a maior cidade do estado, e em circulação desde 1923, e também o Jornal de Santa Catarina, publicado em Blumenau desde $1971^{5}$.

O conceito de Ecologia da Mídia tem se tornado mais importante, nos anos recentes, na pesquisa sobre o desenvolvimento da Mídia. O termo surge, derivado do conceito "ecologia da notícia", em função aos estudos sobre a influência dos blogs, no início dos anos 2002, que colaboram para a formação de uma esfera pública local (ANDERSON, 2016). O principal pressuposto da noção é que o desenvolvimento da mídia só pode ser entendido como um sistema complexo e os efeitos das novas mídias e das novas tecnologias digitais conectadas. A definição de Sistema Complexo Midiático passa por compreender que é um sistema em quais grandes redes de componentes, no caso da mídia, composta por todos os tipos de veículos informativos sejam impressos, eletrônico (TV e Rádio) e estabelecidos em plataformas digitais conectadas, "sem controle central e simples regras de operação, dão origem a comportamentos coletivos complexos, sofisticados processamentos de informação e adaptação via aprendizagem ou evolução" (MITCHELL, 2009, p.13). No sistema da ecologia da mídia, todas as "espécies" são influenciadas quando o equilíbrio é alterado entre diferentes tipos de mídia.

O futuro das informações de relevância social não somente passa pela atuação dos veículos tradicionais de disseminação de notícias com o viés local, mas também pela integração de atores midiáticos no ecossistema informativo ou no conceito estadunidense, na ecologia da mídia. Esses atores surgem de páginas nas redes sociais,

\footnotetext{
${ }^{5}$ Disponível em <https://www.baguete.com.br/noticias/17/10/2019/santa-catarina-perde-jornaisdiarios-impressos > Acessado em 27 de março de 2021
} 
blogs, websites e de ações integradas entre esses meios midiáticos e outras ferramentas disponíveis, como por exemplo plotagem de dados via Google Maps ${ }^{6}$.

Esse ecossistema informativo, com viés de relevância social, está propiciando uma erosão da capacidade jornalística local que sublinha a necessidade de explorar como novas formas de jornalismo hiperlocal colaborativo, sem fins lucrativos e voluntário podem complementar as formas existentes de jornalismo local (JENKINS; NIELSEN, 2018, p. 42).

\section{Comunicação hiperlocal e local}

Com o adensamento de tecnologias digitais conectadas, vivenciamos a cada dia um ecossistema midiático que, embora mais complexo, busca também simplificar o acesso a informações relevantes ao cidadão. Nesse espaço de difícil mensuração, que é a internet, qualquer indivíduo, em qualquer localidade com acesso à Internet, sem restrição governamental, consegue se inserir e atuar virtualmente da maneira que considerar pertinente. Porém, dentro dos escopos tecnológicos permitidos pelos fornecedores de serviços digitais conectados e as normas por eles impostas.

A velocidade de compartilhamentos de audiovisuais, fotos, áudios e demais recursos aumenta drasticamente e esses ativos digitais conseguem ser acessados via dispositivos digitais conectados, alcançando usuários nos mais remotos lugares. A possibilidade de compartilhamento intensifica a comunicação em larga escala, gerando dados e memória em ambiente virtual. Bem como de maneira global, acontecimentos da localidade também geram dados e memória, que podem ser analisados, catalogados e vistos como base de proximidade. Esses dados digitais, ou memórias virtuais, podem ser consultados a qualquer espaço-tempo (CASTELLS, 1999), uma vez que estão dentro da rede e podem ser inseridos em um contexto específico, pertencente a um local ou região.

Esse fenômeno pode ser observado por diversos caminhos interdisciplinares, um deles é o que aponta Marshall McLuhan (1969) ao explicar os processos de 'tribalização", "retribalização" e "destribalização", que são fases de adaptações e readequações frente aos processos comunicacionais. Para McLuhan, a fase da "tribalização" consiste na comunicação oral em um ambiente de curtas distâncias. Assim, a tribo mantinha laços fortes e deveria manter os relatos orais para que não fossem perdidos. Essa fase fortalece o sentido de comunidade. Sobre esse ponto, Michel Maffesoli (2006) expressa que a formação de tribos é realizada a partir de

${ }^{6}$ Google maps. Disponível em < https://www.google.com.br/maps > Acessado em 31 de março de 2021. 
relações diretas de interesses, uma busca por identificação, seja ela afetiva ou por troca de experiências.

A segunda fase, a "destribalização" surgiu na sociedade a partir da escrita e da impressão, uma vez que ambos ampliaram os laços das tribos, e também os enfraqueceram, uma vez que a tribo poderia ter acesso a informações externas e sofrer interferências. Porém, a destribalização possibilitava armazenar memória em lugares além das fronteiras da tribo. Assim, a memória (dados) poderia ser fisicamente armazenada, transportada e acessada. Diferente da tribalização, em que os relatos orais poderiam morrer com quem os carregava em sua memória biológica.

A terceira fase de transformação, segundo McLuhan (1969), é a "retribalização", que possibilitou alargar as conexões, alcançando outras culturas de maneira não-linear, embora se busque relações estreitas com o lugar de pertença, sejam elas relações afetivas, de identificação ou troca de experiências, como propõe Mafessoli (1987). Assim, embora o indivíduo esteja em qualquer lugar do mundo, em qualquer tempo, seria possível regressar à sua 'tribo'. Na retribalização a compreensão da informação sempre seria possível, embora a mesma fosse passada de maneira desconexa e disruptiva.

McLuhan fez essa análise da retribalização observando o rádio e a televisão, porém, podemos ampliar essa análise da terceira fase também para o uso das redes digitais conectas, uma vez que atuamos em um mundo globalizado e amplamente conectado que nos permite o regresso à nossa localidade.

A informação local sempre teve muita força, haja vista que é um dos critérios embasados por teorias que trazem moldes do que deve ou não ser noticiado, conhecido por critérios de noticiabilidade. Alguns autores como Lippiman (1922), Traquina (2005), Sousa Pinto (2009), dentre outros, trazem a importância da informação por proximidade geográfica, ou seja, aquelas demarcadas por fronteiras, por espaços físicos, seja por um bairro, uma cidade, um estado ou país. Em contrapartida, autores como Kasper Stieler (1995 WESTERSTÅHL; JOHANSSON, 1994), Golding-Elliot (1979), Hetherington (1985), Erbolato (1985, 2001), Lage (2006, 2001), Warren e Morton (MORTON; WARREN, 1992), Chaparro (1994), e outros, apontam apenas o fator proximidade - que leva em consideração também os laços afetivos e de pertencimento.

O critério de proximidade nos indica que é importante e recorrente a busca por informações locais. E com o avanço das tecnologias digitais conectadas, vislumbramos como a informação local está enraizado dentro do global, pois, em qualquer tempo e espaço é possível acessar informações de qualquer parte do planeta, inclusive resgatar 
informações da localidade do indivíduo, sendo "essas novas características temporais e espaciais, que resultam na compressão de distâncias e de escalas temporais, estão entre os aspectos mais importantes da globalização a terem efeito sobre as identidades culturais" (HALL, 2014, p.39). Na visão de Stuart Hall, não devemos perceber a localidade como algo amórfico, uma vez que a localidade não é completamente delimitada ou pré-estabelecida, uma vez que está incutida de processos e identidades culturais.

De maneira ampla, a globalização vem "conectando comunidades e organizações em novas combinações de espaço-tempo, tornando o mundo, em realidade e em experiência, mais interconectado" (HALL, 2014, p.39). Dessa forma, a glocalização se caracteriza através da coexistência de fluxos entre os espaços geográficos (locais) e digitais (globais). Ainda para Stuart Hall, a globalização não deve destruir identidades, "é mais provável que ela vá produzir, simultaneamente, novas identificações "globais" e novas identificações "locais" (HALL, 2014, p.45). Assim, surge o indivíduo inserido em contexto "glocal" (global + local). Esse termo criado por Eugênio Trivinho (2007) ponta para a sensação de o indivíduo estar em contato com todo o planeta, sensação essa causada especialmente em decorrência de receber informações basicamente em tempo real, como se as distâncias físicas tivessem de fato diminuído. E em contrapartida, o indivíduo consegue expandir para o global, acontecimentos de sua localidade.

Amparado pela potencialidade e abrangência das redes digitais conectadas, a latência das informações locais e o declínio do jornalismo tradicional, a comunicação hiperlocal vem ganhando força entre comunidades locais. Assim, o hiperlocal "descreve organizações de reportagem de notícias originais orientadas para as comunidades 'geograficamente' nativas da web e destinadas a preencher lacunas percebidas na cobertura de um problema ou região e promover o engajamento cívico (METZGAR; KURPIUS; ROWLEY, 2011, p. 774). Como forma de oposição e crítica ao governo e instituições locais, interagentes (PRIMO; TRASEL, 2006), que são participantes ativos do processo informacional, como jornalistas alternativos, ativistas, aspirantes a jornalistas, entre outros, enxergam na comunicação hiperlocal a oportunidade de produzir matérias de cunho ativo e participativo para descentralizar a informação de veículos de informação consolidados e que por vezes não dão oportunidades de engajamento da população em questões sociais através da informação (WILLIANS; HARTE, 2016). Assim, os interagentes trazem à tona informações que antes não eram pauta discutida amplamente pelas instituições e órgãos do governo.

No entanto, Williams e Harte advertem que, embora seja encorajador e importante que os interagentes produzam jornalismo público, a falta de treinamento e 
também de financiamento podem comprometer essa atividade. Para eles, "à medida que este campo de pesquisa amadurece, acreditamos que uma atenção crítica mais sustentada deve ser dedicada ao estudo das práticas de produção de notícias dos hiperlocais em seus contextos econômicos" (WILLIAMS; HARTE, 2016, p.291. Portanto, existe a possibilidade de cidadãos, sem formação jornalística, poderem ajudar na formação da esfera pública interconectada, produzindo informação de relevância social a partir do contexto social que vivem.

Assim, o jornalismo público, atrelado à mídia hiperlocal, fornece informações mais práticas que fogem ao alcance da comunicação tradicional. Além do mais, amplia a quantidade de meios de informações disponíveis às pessoas, tapando as lacunas de conteúdos e auxilia na definição da identidade local. A internet possibilitou novas rotas informativas e novos meios de comunidades geográficas se conectarem. A acessão a este lugar hiperconectado está mudando o comportamento das audiências e facilitando a produção e compartilhamento/distribuição de conteúdo relevante para sua própria comunidade (RADCLIFFE, 2012). Assim a comunicação hiperlocal vem tratando de temas de relevância social que possuem estreita relação com os moradores e os frequentadores daquela área.

\section{Projeto Lupa NH}

Como descrito anteriormente, o projeto experimental Lupa $\mathrm{NH}$ teve início, em sua modelagem, em 2017, como projeto de extensão na Universidade Federal do Amapá (Unifap). Foi elaborado com objetivo de incentivar e oportunizar a participação cidadã dos estudantes do Bairro Novo Horizonte, em Macapá, por intermédio de tecnologias digitais conectadas. Para isso, adotou-se escopo teórico embasado na comunicação hiperlocal e tecnologias de geolocalização, tendo o dispositivo móvel (celular) como suporte midiático conectado interativo.

Assim, utilizando-se de geolocalização, e por intermédio de aplicativo para celular criado para esta finalidade, os usuários desse sistema podem inserir dados referentes à infraestrutura do bairro como, água potável; coleta e tratamento de esgoto; iluminação pública; calçadas; asfalto; limpeza urbana. Dessa maneira, o usuário do aplicativo alimenta o banco de dados (dataset) que deverá ser utilizado para a construção de notícias por parte dos cidadãos do bairro. Esse processo estabelece uma configuração de ambiente comunicacional e deliberação, propiciando a formação de Inteligência Social Hiperlocal (LIMA JUNIOR, 2017).

Com o objetivo de iniciar o desenvolvimento de aplicativo móvel, ocorreu no laboratório de Webjornalismo, do curso de Jornalismo da Universidade Federal do 
Amapá (Unifap), um Hackthon ${ }^{7}$. A competição, realizada em 8 horas, foi aberta a estudantes de Ciência da Computação, amadores, profissionais ou estudantes de quaisquer universidades. Dessa ação dois integrantes se interessaram na continuidade dos experimentos realizados no evento, o tecnólogo Altemir Almeida e o, então, estudante de Ciências da Computação da Unifap, Felipe Ferreira. O desenvolvimento do aplicativo se consolidou com o trabalho do programador Altemir Almeida, que elaborou a versão 1.0 do sistema, disponibilizado para ser na plataforma Android. Com a ferramenta pronta, foi realizado um workshop de apresentação do aplicativo aos alunos e professores da Escola Raimunda dos Passos Santos para melhor entendimento prático do uso da ferramenta.

Para os testes iniciais em uma zona delimitada do Bairro Horizonte, no dia 16 de novembro de 2018, um grupo de alunos e professores da Escola Raimunda dos Passos Santos, liderados pelo diretor da escola, professor Abdinel Rodrigues Ferreira e pelo professor Lobão Souza, foi a campo para testar o aplicativo e suas funcionalidades. A ação também contou com os, então, alunos do curso de Jornalismo da Unifap, Chirstopher Souza e Dellano Carvalho, que ser tornaram os principais colaboradores do projeto, juntamente com Altemir Almeida. Esse processo de colaboração participante deu origem ao projeto de Trabalho de Conclusão de Curso, "Produto experimental: educomunicação e o jornalismo cidadão na Escola Raimunda dos Passos, Novo Horizonte, a partir do aplicativo hiperlocal Lupa NH (SOUZA; CARVALHO, 2019), orientado pela professora Cláudia Maria Arantes de Assis Saar, a qual tornou-se, colaboradora do projeto.

\section{A capacitação dos alunos para a produção jornalística}

Visando capacitar os alunos da Escola Raimunda dos Passos Santos para utilizar os dados coletados pelo aplicativo Lupa $\mathrm{NH}$, em prol da comunidade, foi realizada capacitação de um grupo de, aproximadamente, 25 alunos do ensino médio da escola. Esse treinamento aconteceu por meio de oficinas que objetivaram a produção de conteúdo informativo de relevância social, nas redes sociais, utilizando-se os dados coletados através do aplicativo para telefone celular Lupa NH. Dessa maneira, foram

\footnotetext{
7 "Hackathon (palavra-valise inglesa, formada pelos vocábulos to hack, 'fatiar', 'quebrar', 'alterar ou ter aces- so a um arquivo ou rede' e marathon, maratona), termo eventualmente aportuguesado para 'hackaton', é uma maratona de programação na qual hackers se reúnem por horas, dias ou até semanas, a fim de explorar dados abertos, desvendar códigos e sistemas lógicos, discutir novas ideias e desenvolver projetos de software ou mesmo de hardware. Por ser um evento público (também referido como hack day, hackfest ou codefest), a maratona dá visibilidade e transparência a essas atividades, além de divulgar os novos produtos gerados". Disponível em: https://goo.gl/mqWwM2. Acessado 3 de abril de 2021.
} 
oferecidas seis oficinas (Fundamentos do jornalismo; Redação Jornalística; Fotojornalismo; Radiojornalismo; Telejornalismo; Convergência Midiática). As oficinas visaram ensinar práticas jornalísticas aos alunos, e que, posteriormente, esse conhecimento pudesse ser repassado para outros alunos e aos cidadãos do bairro. Nesse momento, que o mundo passa pela pandemia de Coronavírus, a continuidade das oficinas e a coleta de dados via aplicativo foram totalmente paralisadas.

Para execução dessa parte do projeto, primeiramente, foi realizada reunião com o diretor Abdinel Ferreira, os professores da escola Raimunda dos Passos Santos, Lobão Sousa e Maria da Conceição Silva Damasceno, com a professora Cláudia Arantes e com os colaboradores Christopher Souza e Dellano Carvalho. Durante a reunião, ficou estipulado que as oficinas deveriam acontecer na própria escola, aos sábados, das $8 \mathrm{~h}$ às $12 \mathrm{~h}$, para não comprometer as atividades curriculares dos alunos. Como o projeto Lupa NH não conseguiu, até o momento, nenhum aporte financeiro via editais, todos os materiais e recursos que não puderam ser disponibilizados pela escola, foram emprestados pelos professores da mesma, como datashow e computador. Além do mais, os professores Maria da Conceição, Lobão e Adbinel prepararam lanches para os alunos durante todas as oficinas, uma vez que o refeitório da escola não funciona aos sábados.

Tendo como base o curso de Jornalismo da Unifap, a preparação das oficinas foi coordenada pela professora Cláudia Arantes e pelos os colaboradores do projeto Lupa $\mathrm{NH}$, Dellano de Carvalho e Christopher Souza, que arregimentaram 12 alunos do curso de jornalismo, os quais se destacaram em disciplinas oferecidas no curso. Esses conteúdos foram formatados para serem ministrados no escopo de oficinas. Assim, o ensino de conteúdo foi justificado pela oportunidade de extração de conhecimento e aprendizagem dessa experiência, além de fornecer condições e oportunidades de conhecimento e percepções sobre o fazer jornalístico aos alunos daquela escola pública. As seis oficinas foram ministradas em duplas para dar maior fluidez e para que fossem mais dinâmicas. Todo material elaborado para a oficina foi previamente submetido, revisado e aprovado pela professora Cláudia Arantes.

Fundamentos do jornalismo foi a primeira oficina oferecida pelos colaboradores do projeto, Christopher Souza e Dellano Carvalho. O objetivo dessa oficina foi explicar sobre dos conceitos básicos do jornalismo, dos direitos humanos, código de ética dos jornalistas e da importância da Lei de Acesso à Informação, visando dar um entendimento geral no papel do jornalista e suas funções enquanto profissional.

A segunda oficina foi a de Redação Jornalística que, por se sua importância, foi dividida em 2 encontros. No primeiro, as alunas Beatriz Melo e Marina Guedes 
abordaram o início da produção e redação jornalística, como: pauta, tipos de fontes, lead, nota, notícia e reportagem. No segundo encontro, as alunas Marina Guedes e Tássia Malena apresentaram o jornalismo literário. Os alunos foram incentivados, durante essa oficina, a produção de textos diversos para a prática da redação jornalística.

A oficina de Fotojornalismo foi ministrada pelos alunos Diego Baleiro e Rudja Santos, que já atuam profissionalmente, e cederam os equipamentos fotográficos deles para ensinarem os alunos a manusearem uma máquina fotográfica profissional. Também foram passados conceitos sobre como produzir boas imagens fotográficas via celular. Durante a oficina, eles, também, ensinaram sobre a história da fotografia e do fotojornalismo, gêneros fotojornalísticos, além de apresentarem fotos que marcaram na história do fotojornalismo e os principais profissionais na área.

Conceitos sobre Radiojornalismo foram ministrados na quarta oficina. Os alunos Pamela Paolla Gualberto e Jomar Magalhães falaram sobre a história do rádio e como ele tem se adaptado às novas tecnologias, demonstraram elementos da escrita radiofônica, leitura e entonação e a usabilidade do podcast. Como prática, os alunos da escola Raimunda dos Passos foram convidados a gravar e editar seus áudios utilizando aplicativos livres para esse fim.

Na quinta oficina tratou-se do Telejornalismo, a qual foi oferecida pelos alunos Benedita Monte, Christopher Souza e Dellano Carvalho, que ensinaram sobre a pauta para a televisão, as características do veículo, a redação para TV, produção e técnicas de gravação e edição.

E por fim, convergência midiática, a sexta oficina, liderada pelos alunos Gilzion Reis e Dioni Willian. Foi trabalhado com os estudantes da escola pública o uso de redes sociais pelo jornalismo, como fazer jornalismo comunitário em redes sociais e como utilizar de maneira mais assertiva o Instagram, Facebook e Whatsapp.

Todas as seis oficinas mostraram teoria e prática jornalística, buscando dar maior conhecimento aos alunos da Escola Raimunda dos Passos Santos para a construção de informações de relevância social no bairro Novo Horizonte.

\section{Tecnologia Lupa NH da versão 1.0 para 2.0}

A primeira versão do aplicativo (1.0), inicialmente elaborada por Altemir Almeida Silva, Felipe Ferreira e Anderson Guerra, e aprimorada e consolidada pelo Altermir Almeida Silva. Para construção do aplilcativo foi utilizado o software Visual Studio 
$\operatorname{Code}^{8}$, na elaboração de todos os códigos do programa. Para facilitar os comandos foi usada a linguagem de programação Javascript ${ }^{9}$, que possibilita recursos mais complexos para seu site como localização em tempo real, o HTML (Linguagem de Marcação de HiperTexto) ${ }^{10}$ e o Cascading Style Sheets (CSS) ${ }^{11}$.

Outra parte importante para a finalidade do aplicativo é o sistema API (Application Program Interface) ${ }^{12}$, a qual é uma interface que interliga serviços e permite acessar dados. No Lupa NH são usados dois, o API de geolocalilzação do Google Maps $^{13}$ para a criação do mapa do bairro a partir dos dados vindos do aplicativo para o banco de dados baseado em MySQL ${ }^{14}$, e a API desenvolvido pelos próprios programadores do projeto. Após isso, o mesmo API repassa para o site todos os dados coletados quando solicitado.

Para que as informações cheguem ao MySQL (Banco de Dados) é necessário a ativação do Sistema de Posicionamento Global, mais conhecido como GPS ${ }^{15}$, pois, o aplicativo utiliza a geolocalização para fazer upload das informações fornecidas pelos moradores.

${ }^{8}$ O Visual Studio Code é um editor de código redefinido e otimizado para criar e depurar aplicativos modernos da web e na nuvem. Disponível em < https://code.visualstudio.com/>. Acessado em 31 de março de 2021.

9 JavaScript (frequentemente abreviado como JS) é uma linguagem de programação interpretada estruturada, de script em alto nível com tipagem dinâmica fraca e multiparadigma (protótipos, orientado a objeto, imperativo e, funcional). Disponível em < https://pt.wikipedia.org/wiki/JavaScript>. Acessado em 31 de março de 2021

${ }^{10}$ HTML (Linguagem de Marcação de HiperTexto) é o bloco de construção mais básico da web. Define o significado e a estrutura do conteúdo da web. Disponível < https://developer.mozilla.org/pt-BR/docs/Web/HTML>. Acessado em 31 de março de 2021

${ }_{11}$ Cascading Style Sheets (CSS) é um mecanismo para adicionar estilo (cores, fontes, espaçamento, etc.) a um documento web. Disponível em < https://pt.wikipedia.org/wiki/Cascading Style Sheets>. Acessado em 31 de março de 2021

12 Interface de Programação de Aplicações (português europeu) ou Interface de Programação de Aplicação (português brasileiro)), cuja sigla API provém do Inglês Application Programming Interface, é um conjunto de rotinas e padrões estabelecidos por um software para a utilização das suas funcionalidades por aplicativos que não pretendem envolver-se em detalhes da implementação do software, mas apenas usar seus serviços. Disponível em < https://pt.wikipedia.org/wiki/Interface de programa $\% \mathrm{C} 3 \% \mathrm{~A} 7 \% \mathrm{C} 3 \% \mathrm{~A} 30$ de aplica\%C3\%A7\%C 3\%B5es>. Acessado em 31 de março de 2021.

${ }_{13}$ Disponível em https://developers.google.com/maps?hl=pt-br. Acessado em 31 de março de 2021.

14 O MySQL é um sistema de gerenciamento de banco de dados (SGBD), que utiliza a linguagem SQL (Linguagem de Consulta Estruturada, do inglês Structured Query Language) como interface. É atualmente um dos sistemas de gerenciamento de bancos de dados mais populares. Disponível em < https://pt.wikipedia.org/wiki/MySQL $>$. Acessado em 31 de março de 2021.

15 O sistema de posicionamento global, mais conhecido pela sigla GPS (em inglês global positioning system), é um sistema de navegação por satélite que fornece a um aparelho receptor móvel a sua posição, assim como o horário, sob quaisquer condições atmosféricas, a qualquer momento e em qualquer lugar na Terra; desde que o receptor se encontre no campo de visão de três satélites GPS (quatro ou mais para precisão maior). Disponível em < https://pt.wikipedia.org/wiki/Sistema de posicionamento global>. Acessado em 31 de março de 2021. 
No aplicativo, o usuário acessa um conjunto de possiblidades de inserção de informações, por intermédio de escolhas, que é dividido em cinco temáticas sobre o bairro, escolhido pelos moradores: água potável, coleta de lixo, saneamento básico, iluminação e asfalto. Com a inserção das escolhas informativas, os dados são enviados através da API para o sistema Google Maps e podem ser visualizados, via retorno de dados geolocalizados (mapa de marcadores), na tela do aplicativo. O sistema está hospedado de forma gratuita e os códigos da sua primeira versão podem ser acessada via plataforma Gythub ${ }^{16}$.

\section{Evolução tecnológica}

A evolução tecnológica do aplicativo Lupa NH para a versão 2.0, ainda em consolidação, tem a finalidade de servir de instrumento para inserção dados locais pela comunidade (informações geolocalizadas, texto, áudio, vídeo, trace route), que abastecerá datasets, alimentando sistemas dotados com tecnologias de "inteligência" computacional (ex: machine learning, recommentation systems, geolocation information systems), com o objetivo de retornar à comunidade informações estruturadas sobre problemas da região, aquecendo os debates deliberativos, portanto, servindo como incentivador da participação da comunidade.

Para que esse escopo tecnológico seja alcançado, foi realizada na primeira etapa, o processo de análise e levantamento dos requisitos. Nessa etapa, o desenvolvimento da plataforma Lupa NH focalizou no levantamento de requisitos através de análise dos cenários, prototipagem rápida e entrevistas não-estruturadas, com o objetivo de considerar as variáveis ambientais e a perspectiva do usuário final. Como resultado desta fase, tivemos 5 requisitos base:

1. Os cenários de utilização devem considerar que o projeto foi concebido para comunidades carentes com infraestrutura básica tecnológica muitas vezes deficiente. Desta forma, deve-se considerar a implementação de mecanismos de armazenamento offline para uso sem conexão de banda larga disponível ou com baixa conectividade, para que uma vez estabelecida a conexão aconteça o sincronismo mantendo a integridade dos dados;

2. Os usuários devem efetuar o acesso, principalmente, por dispositivos móveis, por intermédio de um aplicativo preferencialmente multiplataforma. De acordo com o StatCounter ${ }^{17}$ [1] 85,6\% dos celulares em uso no Brasil possuem Android, o iOS com $14,13 \%$ e outros com aproximadamente $0,3 \%$. Por isso, a priorização de compatibilidade deve ser ordenada para os sistemas Android, iOS e eventual acesso através de softwares navegadores;

3. O Lupa NH deve ser otimizado em seu uso de memória e capacidade de processamento local, devido a existência de possíveis restrições de hardware

${ }^{16}$ Disponível em <https://github.com/wlimair/lupaNH> Acessado em 31 de março de 2021.

17 Disponível em < https://gs.statcounter.com/os-market-share/mobile/brazil > Acessado em 26 de dezembro de 2020. 
nos dispositivos de acesso, optar quando possível por processamento do lado do servidor;

4. O aplicativo necessita de acesso a serviços de mapas do território nacional, aos sensores de geolocalização para o envio de coordenadas geográficas e ter como idioma primário o português;

5. A plataforma deve conter autenticação com usuário de senha segura e a implementação de níveis de acesso. O painel administrativo, será acessado através de softwares navegadores para manipulação dos dados, geração de relatórios e integração com sistemas governamentais de interesse público.

\section{Aplicativo, portal de administração e tecnologias envolvidas}

O projeto Lupa NH é uma plataforma constituída por um aplicativo para celulares e um portal de internet para administração e manipulação dos dados gerenciais. Na primeira versão (1.0), optou-se por um protótipo adequado aos requisitos básicos levantados e uma arquitetura segmentada nos componentes: frontend e backend. $\mathrm{Na}$ camada de frontend está o código de renderização da interface para acesso através de aplicativo de celular e navegadores, já o backend possui todas a regras, validações e APIs de acesso à base de dados.

A linguagem escolhida para os web services de backend foi o PHP (um acrônimo recursivo de Hypertext Preprocesson), linguagem de scripts em código aberto. Os endpoints fazem a integração do aplicativo com o banco de dados relacional mySQL. O Hypertext Markup Language (HTML) e Cascading Style Sheets (CSS) foram utilizados para a criação das interfaces juntamente com o JavaScript para manipulação dos serviços de mapas, validação dos formulários e automatização. O Google Maps foi o serviço em nuvem pública escolhido e o código fonte foi disponibilizado na plataforma GitHub, na conta de /Altemir-Ap e o aplicativo pode ser acessado em https://lupanh.labhacker.org.br/app/. 


\section{arevisto Observatório}

Figura 2: Na esquerda tela com menu inicial e na direita tela para reportar problemas na iluminação pública
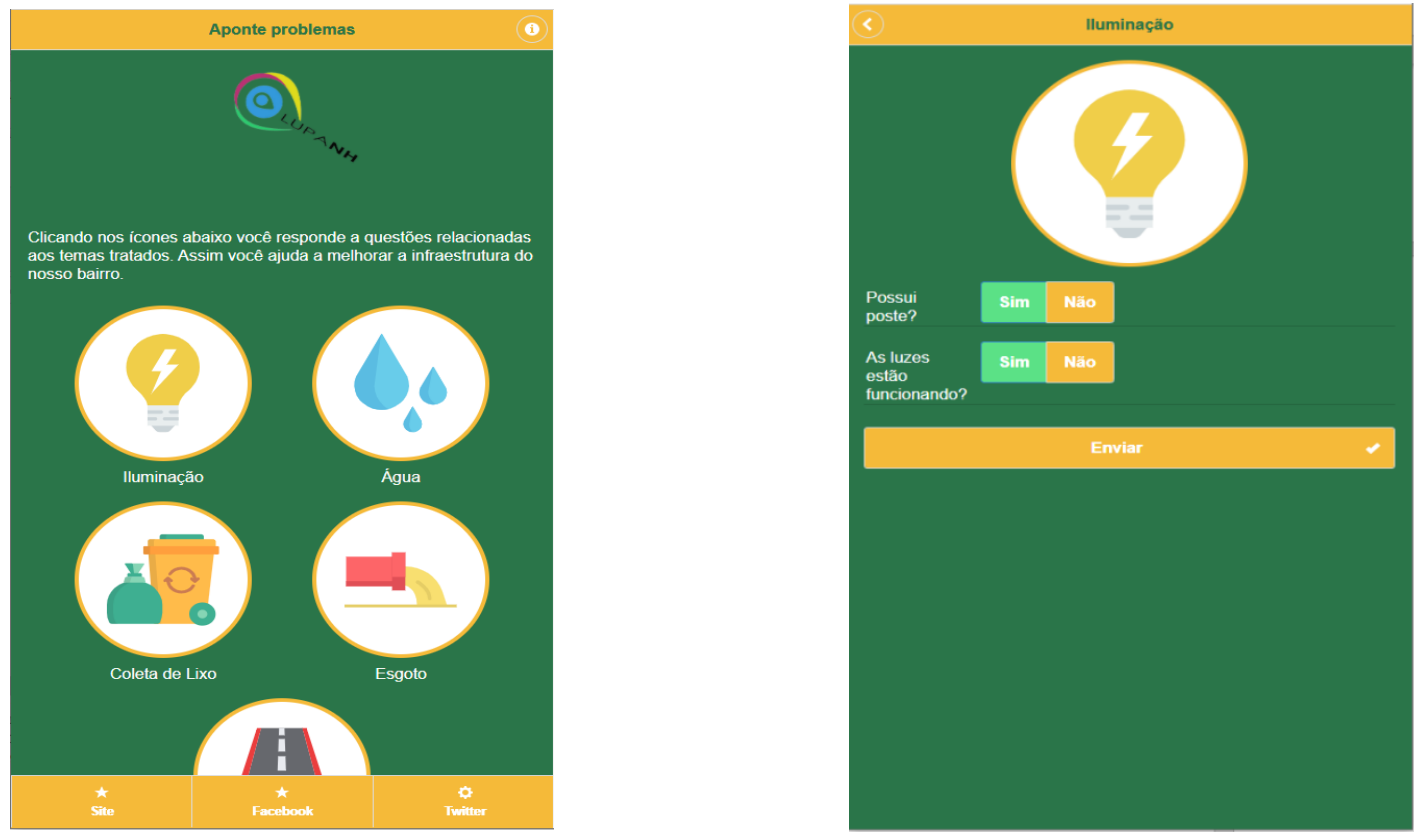

Fonte: Print da tela do aplicativo (desenvolvedores)

Figura 3: Na esquerda tela com mensagem de instrução, ao centro menu tela inicial e a direita tela de informações
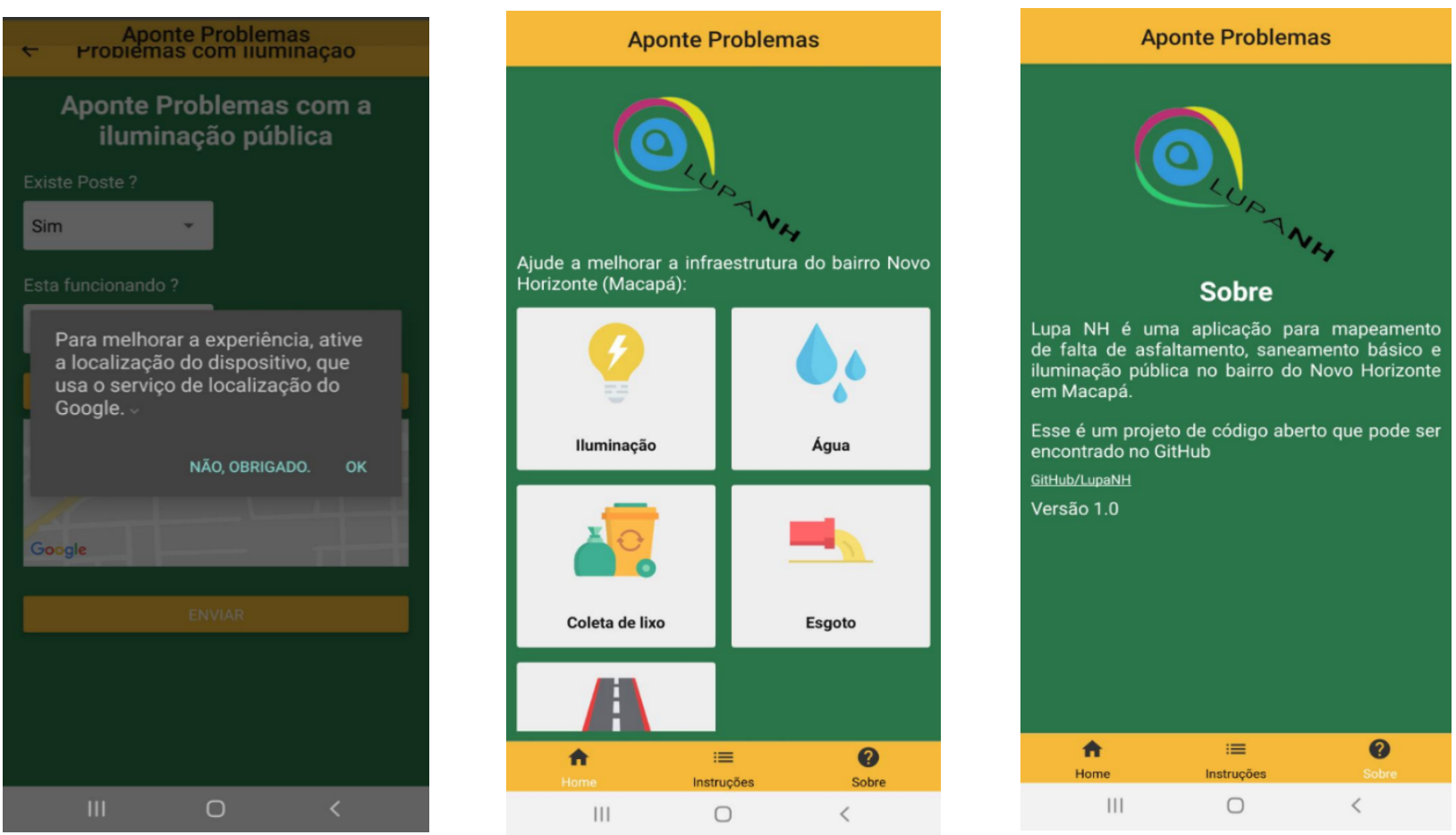

Fonte: Print da tela do aplicativo (desenvolvedores)

A versão 2.0 da plataforma inicia a implementação de uma nova arquitetura ao protótipo baseada na exposição de APIs para acesso atraves de "clientes". Desta forma, 
independente da tecnologia, aplicativo ou software "cliente" todos devem ser capaz de fazer chamadas atraves de um protocolo padrão e ter independencia de ambos lados para acrescentar novas funcionalidades evolutivas. O protocolo escolhido foi Representational State Transfer (REST) desenvolvido por Roy Fielding, protocolo de padrão aberto e com vantagem de não existir amarração entre as liguagens de codificação do backend com dos sistemas que fazem a requisição.

A interação com o serviço de internet foi implementada através do JSON como formato de troca de informações e as operações definidas em métodos HTTP, comumentes usados em arquiteturas REST eles são: GET, POST, PUT, DELETE e PATCH.

O framework de desenvolvimento do backend escolhido foi o .NET CORE, devido ao código aberto e a possibilidade de desenvolvimento para várias plataformas com sem grandes alterações no código. A base de dados escolhida foi o MongoDB, banco não relacional também de código aberto.

Por fim, optou-se por segregar as intefaces administrativas que devem ser acessadas por navegadores dos aplicativos móveis, a principal razão é a otimização da experiência de uso e ganhos em performance. As páginas administrativos continuaram com renderização por HTML e CSS, no entanto, o aplicativo apresentado, na figura 2, foi inteiramente desenvolvido com o framework de JavaScript React Native, devido suas características multiplataforma e o código fonte foi disponibilizado na plataforma GitHub, na conta/wellingtonp.

\section{Perspectivas Futuras}

As futuras versões do Lupa HN podem compensar os déficits técnicos criados pela ausência de profissionais dedicados ao desenvolvimento e restrições orçamentárias que resultaram em poucos requisitos implementados de forma integral. Abaixo listamos alguns itens a considerar como melhorias futuras:

1. Deve-se focar na aplicação de métodos para priorização dos requisitos, numa abordagem metodológica com a avaliação da qualidade do produto de software, segundo a percepção dos usuários (CORDEIRO; FREITAS, 2011);

2. O desenvolvimento iterativo com entregas menores, mas com valor aos usuários finais agregará com maior agilidade e evolução da plataforma;

3. Criar serviços de backend separados conforme padrão de engenharia de software descrito por Sam Newman, desta forma não existe a necessidade de grande customização de interfaces para se adequar aos clientes. Por outro lado, pode-se gerar uma carga adicional administrativa;

4. Aplicação de criptografia ponta-a-ponta devido ao armazenamento e processamento de informações sensíveis dos usuários e posteriormente nas integrações com entidades governamentais; 
5. A implementação da Identidade Federada possibilitará a delegação da autenticação a um provedor terceiro como Facebook, Google, Microsoft, etc. Desta forma, será minimizado o desenvolvimento e administração das credenciais além de facilitar a experiência dos usuários;

6. Publicação nas lojas de aplicativos: Play Store e AppStore.

\section{Conclusões}

A elaboração do projeto Lupa NH possui forte direcionamento para o incentivo da construção da cidadania, por intermédio de ensino sobre técnicas jornalísticas e uso de ferramental tecnológico embasado em sistema computacional móvel (aplicativo), tenho o público-alvo estudantes da Escola Pública Raimunda dos Passos Santos. Essa construção cidadã passa pelo uso da comunicação como função social. Para isso, conta com alunos do ensino médio do Bairro Novo Horizonte, em Macapá, que possui 45 mil habitantes, e com inúmeras dificuldades na sua infraestrutura e de serviços públicos.

O escopo teórico do projeto privilegiou uma modelagem com viés interdisciplinar, para dar conta da complexidade do problema a ser atacado pela pesquisa: falta de dados estruturados sobre a infraestrutura básica no bairro macapaense. Para isso, apontou na direção de produzir aplicativo, para telefones celulares, com o objetivo de fornecer, por intermédio de sistema de geolocalização digital conectado, tecnologia adequada para o propósito elencado no objetivo. $O$ trabalho revisitou conceitualmente os preceitos da comunicação comunitária, pois com as atuais possibilidades tecnológicas, oportuniza aos indivíduos se transformem em produtores de conteúdo informativo de relevância social de forma cidadã. O desafio do projeto e a formação de uma esfera pública interconectada, de forma hiperlocal, com informação de proximidade, funcionando com um sistema de mídia híbrido, o qual está sendo configurado de diferentes formas. Há convivência entre a mídia local e a mídia tradicional, que coexistem de forma interdependente com as novas formas midiáticas, como as redes sociais e os sistemas de comunicação instantânea.

Para participar desse ecossistema informativo, com relevância social local, é necessário a formação de capital social dos agentes de comunicação na escola estadual, o que está sendo realizado, e a evolução tecnológica do aplicativo Lupa NH. Essa nova versão, 2.0, terá a finalidade de servir de instrumento para inserção de dados locais pela comunidade (informações geolocalizadas, texto, áudio, vídeo, trace route), como acontece na versão 1.0, que abastecerá datasets. Mas na versão atualizada, se buscará alimentar o dispositivo com tecnologias de "inteligência" computacional, com o objetivo de retornar à comunidade informações estruturadas sobre problemas da região, aquecendo os debates deliberativos, portanto, servindo como incentivador da participação da comunidade. 


\section{Referências}

ANDERSON, C. W (2016). News ecosystems. In: ANDERSON, T.; DOMINGO, C. W.; DAVID \& HERMIDA, A. (Eds.). . The SAGE handbook of digital journalism. London: SAGE, p. 410-423.

BENKLER, Y. The wealth of networks: how social production transforms markets and freedom. [s.l: s.n.].

BOWMAN, S.; WILLIS, C. Nosotros, el medio: Cómo las audiencias están modelando el futuro de la notícias y la información. Reston, Va: [s.n.]. Disponível em: $<$ https://bit.ly/3jToxog >.

CARDOSO, A. L (2016). Assentamentos precários no Brasil: discutindo conceitos. In: MORAIS, M. D. P.; KRAUSE, C.; NETO, V. C. L. (Eds.). . Caracterização E Tipologia De Assentamentos Precários: Estudos De Caso Brasileiros. Brasília: IPEA, p. 29-52.

CARVALHO, G. M. DE (2013). Crescimento urbano e perda de àreas Verdes em Macapá: riscos e possibilidades de proteção. [s.l.] Universidade Federal do Amapá.

CASTELLS, M (1999). A era da informação: economia, sociedade e cultura - O poder da identidade. Volume 2 ed. São Paulo: Paz e Terra.

CHADWICK, A (2013). The hybrid media system: Politics and power. Oxford: Oxford University Press.

CHAPARRO, M (1994). Pragmática do jornalismo - buscas práticas para uma teoria da ação jornalística. 2. ed. Paz e Terra: Summus.

COLEMAN, S. et al (2016). The mediated city. The news in a postindustrial context. London: Zed books.

CORDEIRO, A. G.; FREITAS, L. P (2011). Priorização de requisitos e avaliação da qualidade de software segundo a percepção dos usuários. Ciência da Informação, v. 40, n. 2, p. 160-179.

ERBOLATO, M (2001). Técnicas de decodificação em jornalismo: redacção, captação e edição no jornal diário. São Paulo: Ática.

GOLDING, P.; ELLIOTT, P (1979). Making the news. London, UK: Longman.

HALL, S (2014). A identidade cultural na pós-modernidade. Rio de Janeiro: Lamparina.

HETHERINGTON, A (1985).. News, Newspapers and Television. London: Macmillan.

JENKINS, J.; NIELSEN, R. K. The Digital Transition of Local News. [s.l: s.n.]. Disponível em: $<$ https://www.digitalnewsreport.org/publications/2018/digital-transition-localnews/>.

LAGE, N (2001). Ideologia e técnica da notícia. Florianópolis: Insular.

LAGE, N (2006). Estrutura da Notícia. São Paulo: Ática.

LIMA JUNIOR, W. T (2017). Inteligência Social Hiperlocal: ambiente comunicacional com dados locais gerados pela comunidade.

LIPPMANN, W (1922). Public opinion. New York, NY: Free Press.

MAFFESOLI, M (2006). O tempo das tribos: o declínio do individualismo nas sociedades de massa. Rio de Janeiro: Forense.

MARCONI, M. DE A.; LAKATOS, E. M (2002). Técnicas de pesquisa. 5. ed. São Paulo: Atlas.

MCLUHAN, M (1969). Os meios de comunicação como extensões do homem. São Paulo: Cultrix.

METZGAR, E. T.; KURPIUS, D. D.; ROWLEY, K. M (2011). Defining hyperlocal media: Proposing a framework for discussion. New Media and Society, v. 13, n. 5, p. 772787.

MITCHELL, M (2009). Complexity: A guided tour. New York, NY: Oxford.

MORAIS, T. O. DE et al (2018). Expansão urbana de Macapá, no Amapá: o caso da zona norte. Planeta Amazônia: Revista Internacional de Direito Ambiental e Políticas Públicas, v. 10, p. 91-101. 


\section{Qrevisto}

Palmas, v. 7, n. 3, p. 1-22, jul.-set., 2021

http://dx.doi.org/10.20873/uft.2447-4266.2021v7n3a12pt

MORTON, L. ; WARREN, J (1992). Proximity: Localization Vs. Distance in PR News Releases. Journalism and Mass Communication, v. 69, n. Quartely.

NYGREN, G.; LECKNER, S.; TENOR, C (2018). Hyperlocals and legacy media media: Ecologies in transition. Nordicom Review, v. 39, n. 1, p. 33-49.

PALHETA, A. C.; SANTOS, T. B. DOS; SERDOURA, F (2016). Segregação ou Integração dos Espaços Públicos Urbanos: uma análise da Zona Norte de Macapá-AP. $7^{\circ}$ Congresso Luso Brasileiro para o Planejamento Urbano, Regional, Integrado e Sustentável-Contrastes, Contradições e Complexidades.

PERUZZO, C. M. K (2007). Direito à comunicação comunitária, participação popular e cidadania. v. 1, n.1 ed. Juiz de Fora (MG): Lumina.

RADCLIFFE, D [s.n.]. Here and Now: UK hyperlocal media today. London, UK.

RUDIO, F. V (1986). Introdução ao Projeto de Pesquisa Científica. Petrópolis: Vozes.

SOUSA PINTO, A. E (2009). Jornalismo diário. São Paulo: Publifolha.

SOUZA, C. F. DE; CARVALHO, D. R. B. DE (2019). Produto experimental: educomunicação e o jornalismo cidadão na Escola Raimunda dos Passos, Novo Horizonte, a partir do aplicativo hiperlocal Lupa NH. [s.l.] Universidade Federal do Amapá.

TRAQUINA, N (2005). Teorias do jornalismo - Volume II: A tribo jornalística - uma comunidade interpretativa transnacional. Florianópolis: Insular.

WESTERSTÅHL, J.; JOHANSSON, F (1994). Foreign news: News values and ideologies. European Journal of Communication, v. 9, p. 71-89.

WILLIANS, A.; HARTE, D (2016). Hyperlocal News. In: WITSCHGE, T. et al. (Eds.). . The SAGE Handbook of Digital Journalism. City Road, London: SAG,. p. 1-595.

\section{ABSTRACT:}

The article analyses the evolution of the Lupa $\mathrm{NH}$ experimental project, with the involvement of teachers and students from the Raimunda dos Passos Santos State School (Amapá/AP). The project aims to create a system for the configuration of the communicational environment and deliberation for the formation of Hyperlocal
Social Intelligence, aiming the collaboration in the insertion of data hyperlocal, and production of journalistic contend with the civic / citizen bias of students, residents, and frequenters of the region, supplying local databases by mobile devices. In the following areas: drinking water; sewage collection and treatment; Street lighting; sidewalks; asphalt; urban cleaning. The 


\section{revisto Observatório}

paper describes the improved development of version 2.0

KEYWORDS: Hyperlocal; Journalism; App, Citizen; Lupa NH

\section{RESUMEN:}

El artículo analiza la evolución del proyecto experimental Lupa $\mathrm{NH}$, con la participación de profesores y alumnos de la Escuela Estatal Raimunda dos Passos Santos (Amapa / AP). El proyecto tiene como objetivo crear un ambiente comunicacional (conversación) y deliberación para la formación de Inteligencia Social Hiperlocal, con el objetivo de colaborar en la inserción de datos hiperlocales y producción de contenido periodístico con el sesgo cívico / ciudadano, suministrando bases de datos locales, mediante una aplicación personalizada para dispositivos móviles, con información sobre infraestructura en las siguientes áreas: agua potable; recolección y tratamiento de aguas residuales; iluminación pública; aceras; asfalto; limpieza urbana. El documento describe el desarrollo mejorado de la versión 2.0.

PALABRAS-CLAVES: Hiperlocal; Periodismo; aplicación movil; Ciudadano; Lupa NH. 